\title{
An Assessment of Taxonomic Congruence between DNA-DNA Hybridization and Pyrolysis Gas-Liquid Chromatographic Classifications
}

\author{
By A. G. O'DONNELL, ${ }^{1 *}$ H. J. H. MACFIE ${ }^{2}$ AND J. R. NORRIS ${ }^{3}$ \\ ${ }^{1}$ Department of Soil Science, The University, Newcastle upon Tyne NEI 7RU, UK \\ ${ }^{2}$ Institute of Food Research, Bristol Laboratory, Langford, Bristol BS18 7DY, UK \\ ${ }^{3}$ Cadbury Schweppes Ltd, Lord Zuckerman Research Centre, The University, Whiteknights, \\ Reading RG6 2AD, UK
}

(Received 28 August 1987; revised 19 October 1987)

\begin{abstract}
The existence of subgroups within Bacillus megaterium has been reported previously on the basis of DNA-DNA hybridization and DNA base composition studies. In this study the strains used to define these subgroups have been reanalysed by pyrolysis gas-liquid chromatography. The resultant two-group classification of the test strains was directly comparable with that obtained from the previous nucleic acid analyses at the between-group level. However, comparisons of the test strains at the within-group level proved less successful.
\end{abstract}

\section{INTRODUCTION}

Developments in microbial systematics have been accompanied by an increasing diversity in the techniques used to classify and identify micro-organisms. In many cases the new techniques are evaluated with respect to the existing taxonomy of the organisms, which may have been derived using a completely different measure or index of taxonomic association. Examples of the problems involved include comparisons between numerical phenetic classifications and those obtained using chemotaxonomic procedures such as lipid analysis (Bousfield et al., 1983; O'Donnell et al., 1985), electrophoretic techniques (Feltham \& Sneath, 1979; Jackman, 1985) and RNA cataloguing (Stackebrandt \& Woese, 1981). In many cases these comparisons have been performed qualitatively with no statistical treatment of the results.

By examining similarities in the molecular structure of nucleic acid, DNA hybridization techniques are generally regarded as providing a reliable indication of the relationships between different micro-organisms. Previous studies (O'Donnell et al., 1980a, b; O'Donnell \& Norris, 1981) have demonstrated the value of pyrolysis gas-liquid chromatography (PyGC) in the classification of the genus Bacillus. One of these reports (O'Donnell et al., 1980a) showed that given suitable statistical analysis, PyGC can be used to recover taxonomic structures similar to those defined using DNA hybridization. However, it remains uncertain whether the congruence found at the taxon level between data obtained from the analysis of DNA and those derived from pyrolysis studies exists when comparing the relationships among individual strains.

The present study was designed to examine this relationship by using PyGC to analyse the same strains as those studied by Hunger \& Claus (1981) when demonstrating two major subgroups of Bacillus megaterium using DNA-DNA hybridization and DNA base composition techniques.

\section{METHODS}

Organisms. The test strains (Table 1) were grown at $30^{\circ} \mathrm{C}$ on nutrient agar (Oxoid) for $5 \mathrm{~d}$, until well sporulated. Organisms were grown on membrane filters (HAWP $0470.45 \mu \mathrm{m}$, Millipore) as reported previously (O'Donnell $e t$ al., 1980a). The strains studied were the same as those investigated by Hunger \& Claus (1981). Strains 1-11 belonged to homology group A of Hunger \& Claus (1981) and strains 13-15, 17 and 18 to their homology group B. 
Table 1. B. megaterium strains studied, level of replication, degree of DNA-DNA hybridization and difference in base composition from DSM 333

$\begin{array}{ccccc}\begin{array}{c}\text { Strain } \\ \text { no. }\end{array} & \text { Source } \dagger & \begin{array}{c}\text { Replicates } \\ \text { in PyGC }\end{array} & \begin{array}{c}\text { DNA homology } \\ \text { value and group } \ddagger\end{array} & \begin{array}{c}\text { Difference in } \\ \text { mol } \% \text { G }+ \text { C } \ddagger\end{array} \\ 1 & \text { DSM 32* } & 4 & 87, \text { A } & 0 \cdot 4 \\ 2 & \text { DSM 90 } & 4 & \text { ND, A } & \text { ND } \\ 3 & \text { DSM 319 } & 3 & 95, \text { A } & 0 \cdot 5 \\ 4 & \text { DSM 321 } & 4 & 80, \text { A } & 0 \cdot 2 \\ 5 & \text { DSM 322 } & 4 & 79, \mathrm{~A} & 0 \cdot 3 \\ 6 & \text { DSM 333 } & 4 & 100, \mathrm{~A} & 0 \\ 7 & \text { DSM 337 } & 4 & 85, \mathrm{~A} & 0 \cdot 1 \\ 8 & \text { DSM 339 } & 4 & 87, \mathrm{~A} & 0 \cdot 2 \\ 9 & \text { DSM 344 } & 4 & 86, \mathrm{~A} & 0 \cdot 0 \\ 10 & \text { DSM 509 } & 3 & 78, \mathrm{~A} & 0 \cdot 6 \\ 11 & \text { DSM 510 } & 3 & 84, \mathrm{~A} & 0 \cdot 3 \\ 12 & \text { DSM 1316 } & 4 & 30,- \text { - } & 0 \cdot 2 \\ 13 & \text { DSM 1317 } & 4 & 22, \mathrm{~B} & 3 \cdot 3 \\ 14 & \text { DSM 1318 } & 4 & \text { ND, B } & \text { ND } \\ 15 & \text { DSM 1319 } & 4 & 30, \mathrm{~B} & 2 \cdot 7 \\ 16 & \text { DSM 1320 } & 3 & 33,- & 1 \cdot 2 \\ 17 & \text { DSM 1321 } & 3 & 34, \mathrm{~B} & 2 \cdot 5 \\ 18 & \text { DSM 1323 } & 4 & 28, \mathrm{~B} & 2 \cdot 6\end{array}$

† DSM, Deutsche Sammlung von Mikroorganismen, Göttingen, FRG. The asterisk denotes the type strain. $\ddagger$ Data obtained from study by Hunger \& Claus (1981) (comparisons relative to DSM 333); ND, not determined.

Strains 12 and 16 belonged to neither homology group. Strains were grown twice. Two replicates from each plate were applied directly to Curie-point wires (O'Donnell \& Norris, 1981) and allowed to dry in air.

Chromatography. Chromatographic analysis was done with a Pye Unicam 204 gas chromatograph fitted with $2.6 \mathrm{~m} \times 5 \mathrm{~mm}$ (i.d.) dual columns, packed with $5 \%$ (w/w) Carbowax 20M-TPA on Chromosorb G, 80-100 mesh, AW-DMCS (Phase Separations). Pyrolysis was carried out in a stream of nitrogen $\left(20 \mathrm{ml} \mathrm{min}^{-1}\right)$ at $610^{\circ} \mathrm{C}$ for $4 \mathrm{~s}$ using a Pye Unicam pyrolyser compatible with the 204 series gas chromatograph. An injection temperature of $250{ }^{\circ} \mathrm{C}$ was used. Following an initial hold at $75^{\circ} \mathrm{C}$ for $2 \mathrm{~min}$, the oven temperature was increased at $8{ }^{\circ} \mathrm{C} \mathrm{min}^{-1}$ to $200^{\circ} \mathrm{C}$ and held at that temperature. Raising the temperature to $230^{\circ} \mathrm{C}$ after an analysis removed the compounds of higher boiling point, thereby cleaning the column. The total analysis time was approximately $50 \mathrm{~min}$. The output from the column was detected using a flame ionization detector at an attenuation of 128 and recorded at $1 \mathrm{~cm} \mathrm{~min}{ }^{-1}$ simultaneously on two chart recorders set at $10 \mathrm{mV}$ and $50 \mathrm{mV}$ full-scale deflection, respectively.

Each pyrogram was represented by 22 peaks which were present on all of the pyrograms in the data base. To eliminate differences between pyrograms due to variations in sample size, a standardization procedure was used in which each peak involved in the analysis was divided by the sum of the chosen set of peaks and the resultant quotient multiplied by 1000 . In this way each of the selected peak heights was represented as a fraction of the sum of chosen peaks and pyrograms of different sample size could be compared. For the purposes of the statistical methods the analyses representative of each strain were averaged.

Data analysis. (a) Cluster analysis. The relationship between the pyrolysis profiles of the test strains was determined by applying cluster analysis to the averaged peak heights of the replicates. Similarities were calculated using the Gower coefficient $\left(S_{\mathrm{G}}\right)$ and clustered using the unweighted average linkage clustering algorithm (Sneath \& Sokal, 1973).

(b) Relating nucleic acid and PyGC data. Hunger \& Claus (1981) used strain DSM 333 as the source of reference DNA for $B$. megaterium group A in both the mol $\% \mathrm{G}+\mathrm{C}$ studies (determining the difference in mol $\% \mathrm{G}+\mathrm{C}$ between the test strains and DSM 333) and the DNA hybridization analyses. It was therefore necessary to express the differences among the corresponding pyrolysis spectra in the same way for comparative purposes. The differences were expressed relative to DSM 333 using two different methods.

(i) Euclidean distance:

$$
E_{\mathrm{ij}}^{2}=\left(x_{\mathrm{i}}-\bar{x}\right)^{\mathrm{r}}\left(x_{\mathrm{j}}-\bar{x}\right)
$$

where $x_{\mathrm{i}}, x_{\mathrm{j}}$ are the vectors of length 22 containing the replicate means of each peak for strains $\mathrm{i}, \mathrm{j}$ respectively, and $\bar{x}$ is the overall mean vector (T stands for transpose).

(ii) Mahalanobis distance:

$$
D_{\mathrm{ij}}^{2}=\left(x_{\mathrm{i}}-\bar{x}\right)^{\mathrm{T}} W^{-1}\left(x_{\mathrm{j}}-\bar{x}\right)
$$

where $\boldsymbol{W}$ is the $22 \times 22$ pooled within-strain variance covariance matrix. 
The Mahalanobis distance has four theoretical advantages over the Euclidean. First, the correlation between the peaks is taken into account. Thus the addition of another peak into the calculations will only increase the distance if its within-strain variation cannot be accounted for by the variation in the other peaks. The second advantage is that the distance is independent of the scaling of the peaks. The third advantage is that the replicate information is used in forming the distance and will tend to weight down those peaks heavily influenced by variations in the pyrolysis process. The fourth advantage is that the distance expresses the number of replicate standard deviations between two group means. Thus ordinary statistical tests are easily applied. For our purposes a distance of 4 or more between two sample sets implies that their replicates will rarely overlap. The Euclidean and Mahalanobis distances from DSM 333 were extracted from the respective inter-distance matrices and plotted against the corresponding hybridization or $\mathrm{mol} \% \mathrm{G}+\mathrm{C}$ difference data. The within-group correlations were then examined in the same way for each group and its associated reference strain. All of the statistical analyses were performed using the GENSTAT statistical package (Alvey et al., 1977).

\section{RESULTS}

The result of the average linkage cluster analysis on the pyrolysis data is shown in Fig. 1. One minor and two major clusters are evident at the $70 \%$ similarity level. One of the major clusters contained all the strains received as $B$. megaterium group A (strains $1-11$ ) although strain 16 (DSM 1320), which was thought to belong to neither B. megaterium group, was also recovered in this cluster. Strains 8 (DSM 339) and 16 (DSM 1320), which clustered together at the 78\% similarity level, appeared to be outliers of $B$. megaterium group A. The other main cluster defined at the $70 \%$ similarity level contained four of the five $B$. megaterium group B strains (13, $14,17,18$ ). The remaining strain (DSM 1319, strain 15) clustered with strain 12 (DSM 1316) at the $78 \%$ similarity level to form a minor cluster which formed an aggregate group with $B$. megaterium group $\mathrm{A}$ at the $66 \%$ similarity level. Fig. 1 reveals that group $\mathrm{A}$ is more homogeneous than group B. The cophenetic correlation was 0.89 .

The magnitude of the strain variation relative to replicate variation is shown in graphical form by plotting all replicate pyrograms relative to the first two canonical variates using strain membership as the group structure (Fig. 2). Such an approach has been used previously in the discriminant analysis of pyrolysis mass spectra (Windig et al., 1983). This plot accounts for $74 \%$ of the between-strain variance in Mahalanobis space. Inclusion of the third canonical variate, represented by the arrows, results in the recovery of $83 \%$ of the between-strain variance. Fig. 2 is a close approximation of the dendrogram in Fig. 1 but because of the different distance measures

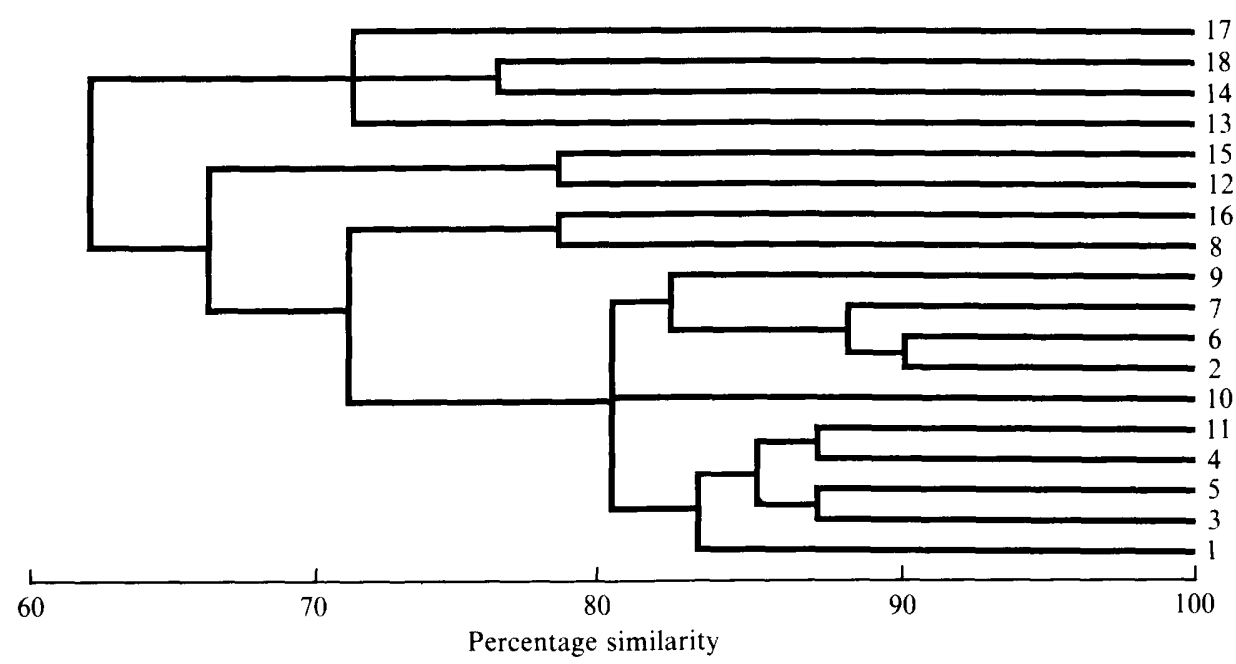

Fig. 1. A dendrogram showing the relationship between the test strains analysed by PyGC. Similarities were calculated using the Gower coefficient and clustered using average linkage. Co-phenetic correlation $=0.89$. 


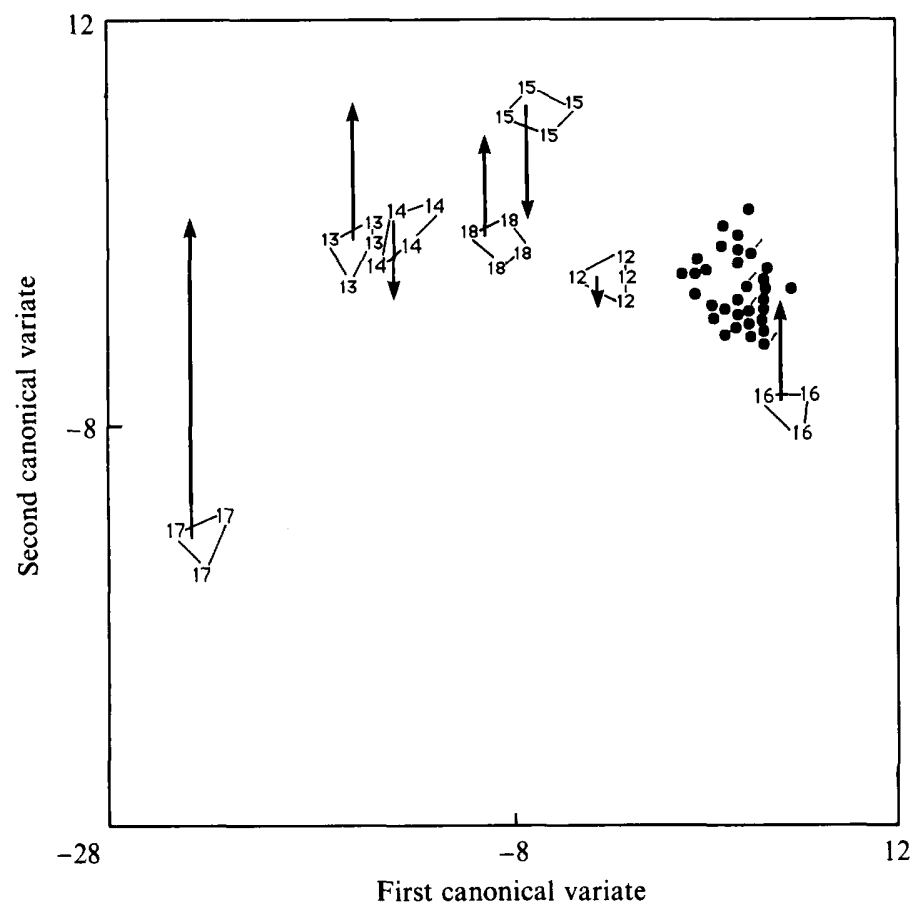

Fig. 2. Canonical variates analysis on the PyGC data of 18 strains of $B$. megaterium. Sample membership has been used to group the replicates which have been linked together. Vertical arrows indicate major departures on the third canonical axis. O, Positions of the strains representing homology group $\mathrm{A} ; \mathbf{O}^{\prime}$, co-incident points.

and the influence of replicate variance it does not reproduce the between-strain relationships exactly. Strains 12 and 16 are equally close to group A but in quite different directions.

\section{Comparison of PyGC with DNA hybridization and mol \% G $+C$ composition}

Strains 2 and 14 were excluded from these comparisons since details of their DNA hybridization and $\mathrm{mol} \% \mathrm{G}+\mathrm{C}$ relative to DSM 333 were not available. The reference strain 6 (DSM 333) does not appear since all comparisons give zero values. Fig. 3( $a, b)$ shows the result of plotting the degree of binding to DSM 333 (vertical axis) against the distance measure derived from both the Euclidean (Fig. $3 a$ ) and Mahalanobis (Fig. $3 b$ ) distance between spectra. In Fig. $3(a)$, the division between group A and group B evident in the hybridization data is reflected in the PyGC results. Strains 12 and 16 lie between groups A and B on the PyGC axis but are not discernibly different on the DNA hybridization axis. Fig. 3(b) shows a good separation between groups $A$ and $B$ using the pyrolysis techniques, with strains 12 and 16 showing a greater affinity to group $A$.

Figs $4(a)$ and $4(b)$ show the same pyrolysis data plotted against the difference in mol $\% \mathrm{G}+\mathrm{C}$ base composition of the test strains from DSM 333. With respect to the nucleic acid data, strain 16 is recovered as an intermediate whereas strain 12 is recovered in group A. This is accurately reflected on the axis representing the Euclidean distances of the test strains from DSM 333 (Figs $3 a$ and $4 a$ ) but the Mahalanobis distances do not separate strain 16 very well.

\section{Testing of within-group congruence}

Inspection of these plots in Figs 3 and 4 indicates no evidence of significant correlation in group B between either DNA homology or $\mathrm{mol} \% \mathrm{G}+\mathrm{C}$ and the pyrolysis-derived distance measure. This can probably be explained by the fact that comparisons were made using 

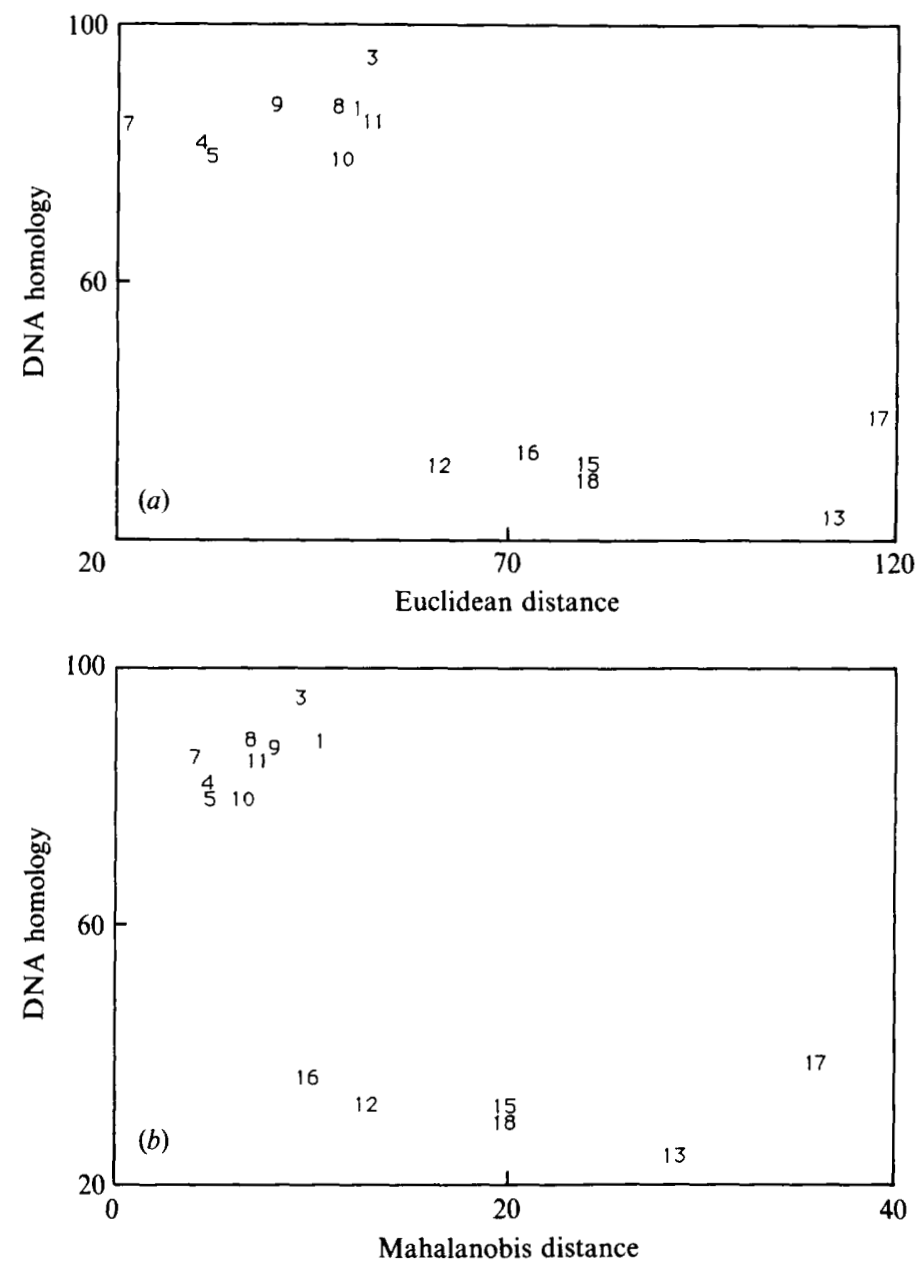

Fig. 3. (a) Plot of DNA homology with DSM 333 calculated against Euclidean distance from DSM 333 calculated using the pyrolysis data. (b) Plot of DNA homology with DSM 333 against Mahalanobis distance from DSM 333 calculated using the pyrolysis data.

hybridization and $\mathrm{mol} \% \mathrm{G}+\mathrm{C}$ data on a group A reference strain. DNA homology and differences in $\mathrm{mol} \% \mathrm{G}+\mathrm{C}$ are known to be particularly unreliable between strains belonging to different species. Insufficient homology and $\mathrm{mol} \% \mathrm{G}+\mathrm{C}$ data made it impossible to extend the present study to include a reference strain from group $\mathrm{B}$.

In group A there is a trend for both DNA homology $(r=-0.41$ for Euclidean and -0.67 for Mahalanobis) and $\mathrm{mol} \% \mathrm{G}+\mathrm{C}(r=0.59$ for Euclidean and 0.28 for Mahalanobis $)$. Since strains 12 and 16 have been excluded from the calculations there are only 7 degrees of freedom and statistical significance testing is not meaningful. It is sufficient to note that there is some evidence of congruence that needs to be confirmed by further experimentation.

\section{DISCUSSION}

The data presented in this study support the findings of Hunger \& Claus (1981) that the $B$. megaterium taxon is heterogeneous. Each plot provides evidence for at least two distinct clusters although, in accordance with the DNA-DNA hybridization data, the correct classification of strains 12 (DSM 1316) and 16 (DSM 1320) remains unclear. All of the plots indicate that the 

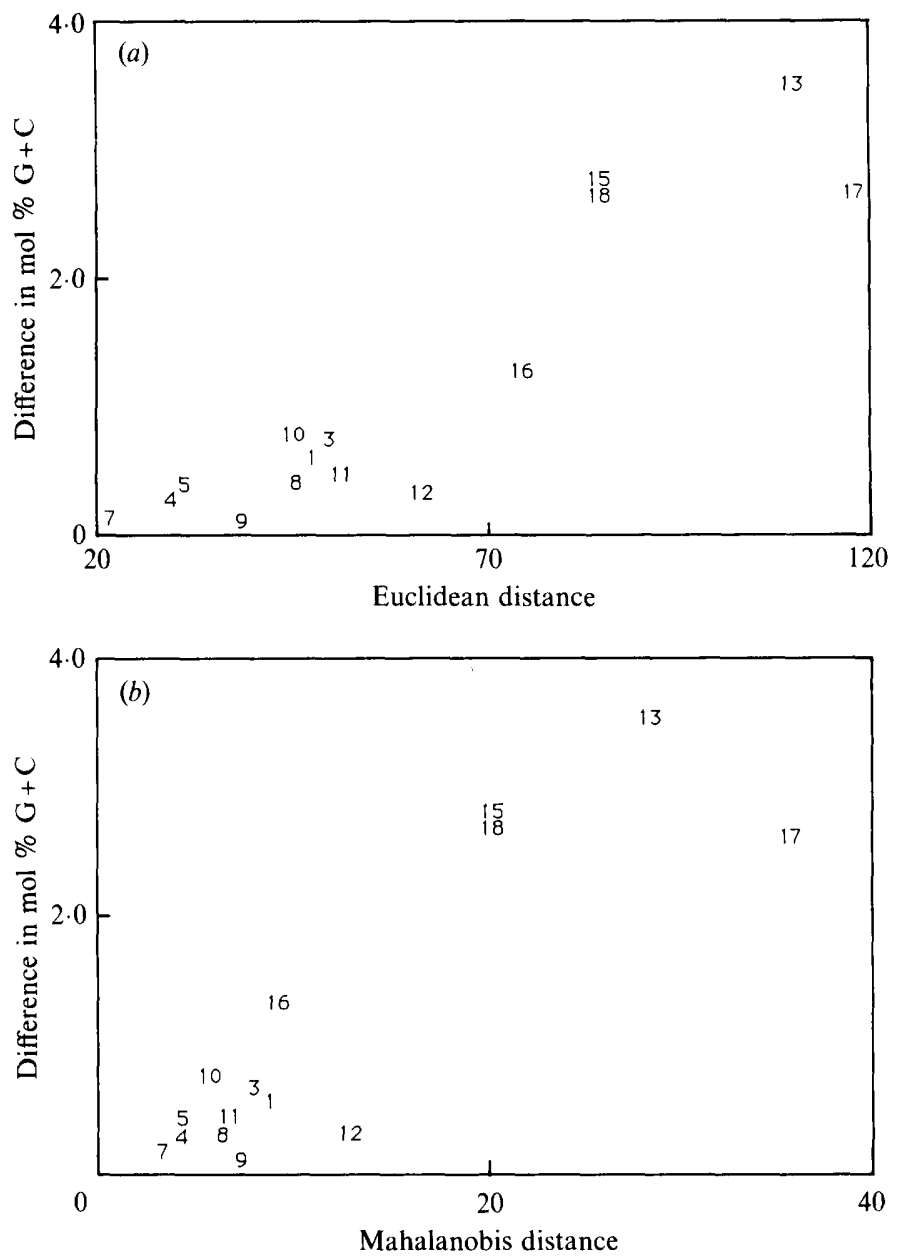

Fig. 4. (a) Plot of the difference in mol $\% \mathrm{G}+\mathrm{C}$ from DSM 333 against Euclidean distance from DSM 333 calculated using the pyrolysis data. (b) Plot of the difference in $\mathrm{mol} \% \mathrm{G}+\mathrm{C}$ from DSM 333 against Mahalanobis distance from DSM 333 calculated using the pyrolysis data.

pyrolysis profiles in group A are more homogeneous than those in group B. Differences in the between-strain relationships found by Euclidean or Mahalanobis distance indicate that the scaling is having an effect. The choice of distance metric is fairly arbitrary since both have advantages. Euclidean distance between two pyrograms is a close representation of the overall difference if they were to be compared visually. The Mahalanobis distance is used to express the difference between two or more sets of pyrograms and is more interpretable. Analysing pyrolysis data using Mahalanobis distances provides an alternative method of calculating similarities between pyrograms and may be particularly valuable in identification and taxonomic mapping studies when replicate information is avaiiable. Such an approach can also be applied to quantitative data obtained using other taxonomic techniques such as gas chromatography and gel electrophoresis.

It is generally accepted that DNA-DNA hybridization data are primarily of importance in the investigation of taxonomic relationships within and between species, although the statistical significance of species based on such data has not been rigorously tested (Owen \& Pitcher, 1985). It is against such a background that the analysis of within-group congruence carried out in the present study should be evaluated. For the purposes of this paper, it has been assumed that since 
all the nucleic acid analyses were performed using the same hybridization and base composition procedures, differences in hybridization and $\mathrm{mol} \% \mathrm{G}+\mathrm{C}$ reflected genetic differences between the test strains and DSM 333. The limitation of such an assumption is demonstrated by the fact that strains in which the mol $\% \mathrm{G}+\mathrm{C}$ is closest to that of DSM 333 do not show the highest hybridization values with this strain. Therefore, there is already a lack of congruence between the hybridization data and the base composition results (Hunger \& Claus, 1981).

The results of the present study demonstrate that although capable of recovering similar structures at higher taxonomic levels, pyrolysis and nucleic acid procedures are not directly comparable at the strain level. However, given our present understanding of the significance of nucleic acid studies within taxa and the complexity of the pyrolysis profiles, such a result is perhaps not too surprising.

\section{REFERENCES}

Alvey, W. G., Banfield, C. F., Baxter, R. I., Gower, J. C., Krzanowski, W. J., Lane, P. W., Leech, P. K., Welder, J. A., Payne, R. W., Phelps, K. M., Rogers, C. E., Ross, G. J. S., Simpson, H. R., Todd, A. D., WedDerburn, R. W. M. \& WilkiNsON, G. N. (1977). GENSTAT Reference Manual. Harpenden, UK: Rothamsted Experimental Station.

Bousfield, I. J., Smith, G. L., Dando, T. R. \& Hobbs, G. (1983). Numerical analysis of total fatty acid profiles in the identification of coryneform, nocardioform and some other bacteria. Journal of General Microbiology 129, 375-394.

Feltham, R. K. A. \& Sneath, P. H. A. (1979). Quantitative comparison of electrophoretic traces of bacterial proteins. Computers and Biomedical Research 12, 247-263.

Hunger, W. \& Claus, D. (1981). Taxonomic studies on Bacillus megaterium and an agarolytic Bacillus strain. In The Aerobic Endospore-forming Bacteria, Classification and Identification, pp. 217-239. Edited by R. C. W. Berkeley \& M. Goodfellow. London: Academic Press.

JACKMAN, P. J. H. (1985). Bacterial taxonomy based on electrophoretic whole-cell protein patterns. In Chemical Methods in Bacterial Systematics, pp.115128. Edited by M. Goodfellow and D. E. Minnikin. London: Academic Press.

O’Donnell, A. G. \& Norris, J. R. (1981). Pyrolysis gas-liquid chromatographic studies in the genus Bacillus. In The Aerobic Endospore-forming Bacteria, Classification and Identification, pp. 141-179. Edited by R. C. W. Berkeley \& M. Goodfellow. London: Academic Press.

O'DONNEll, A. G., NorRis, J. R., Berkeley, R. C. W.,
Claus, D., Kaneko, T., Logan, N. A. \& Nozaki, R. (1980a). Characterization of Bacillus subtilis, Bacillus pumilus, Bacillus licheniformis and Bacillus amyloliquefaciens by pyrolysis gas-liquid chromatography and by deoxyribonucleic acid (DNA)-DNA hybridization, biochemical tests and API systems. International Journal of Systematic Bacteriology 30, 448-459.

O'Donnell, A. G., MAcFie, H. J. H. \& NorRis, J. R. $(1980 b)$. An investigation of the relationship between Bacillus cereus, Bacillus thuringiensis and Bacillus mycoides using pyrolysis gas-liquid chromatography. Journal of General Microbiology 119, 189 194.

O’Donnell, A. G., NaHaie, M. R., Goodfellow, M., Minnikin, D. E. \& HAJEK, V. (1985). Numerical analysis of fatty acid profiles in the identification of staphylococci. Journal of General Microbiology 131, $2023-2033$.

OWEN, R. J. \& PITCher, D. (1985). Current methods for estimating DNA base composition and levels of DNA-DNA hybridization. In Chemical Methods in Bacterial Systematics, pp.1-15. Edited by M. Goodfellow and D. E. Minnikin. London: Academic Press.

SNEATH, P. H. A. \& SoKal, R. R. (1973). Numerical Taxonomy: the Principles and Practice of Numerical Classification. San Francisco: W. H. Freeman.

Stackebrandt, E. \& Woese, C. R. (1981). The evolution of prokaryotes. Symposia of the Society for General Microbiology 32, 1-31.

Windig, W., Hasserkamp, J. \& Kistemaker, P. G. (1983). Interpretation of sets of pyrolysis mass spectra by discriminant analysis and graphical rotation. Analytical Chemistry 55, 81-88. 